chief ingredients of natural aperient waters, there must be thousands of people who take every week one and two ounces for a dose and feel no bad effects. The sale of Epsom salts at chemists' shops every Saturday is enormous, to say nothing of the cases where four ounces is frequently taken for a single dose by pregnant women in the hope of bringing on an abortion. The question is certainly one of interest, but why a fatal toxic action should be brought about in a few cases is a question I am not prepared to answer.

I have recently had under observation at Dr. T. D. Savill's clinic at St. John's Hospital for Diseases of the Skin two cases of verruca plana of the hands and face, one of which has been successfully treated by Epsom salts. The first case was that of a girl, aged 20 years, who presented herself at the skin hospital on Feb. 3rd of this year suffering from warts of six years' duration. Upon inspection the dorsal surface of both hands was covered with warts of considerable size, while in addition there were a few scattered ones on the neck and around the mouth. She was put on Epsom salts in drachm doses thrice daily, no external application was given, and by March 24th the warts had entirely disappeared. The second case was a little boy, aged four years, seen on April 21st, suffering from warts of seven months' duration. The dorsal surface of both hands was much affected with them and a few were also to be seen about the mouth. He was treated with Epsom salts in drachm doses twice daily, but as he has only been under treatment for this short period there is no marked effect at present, but I have no hesitation in saying that in the course of a few weeks more they will have entirely disappeared.

Some 15 years ago I treated a little girl, aged ten years, for extensive warts of the face and body. I gave her Epsom salts in drachm doses twice daily for over three months; at the end of this time the whole of the warts had entirely vanished. None of these cases have ever complained of any unpleasant symptoms.-I am, Sir, yours faithfully,

Croydon, May 6th, 1909.

J. B. RIDLEY, M.D. Edin.

\section{OTITIS MEDIA AS A COMPLICATION WHOOPING-COUGH.}

7o the Editor of THE LANCET.

SIR,-Although we do not find otitis media given as a complication of pertussis, surely it is by no means a rare condition. I have frequently noted it, and during this past winter during an epidemic I have had over a score of cases. All these cases developed the ear trouble at the beginning of the spasmodic stage. There was little possibility that the trouble was the ordinary otitis media of infants and young children. I am, Sir, yours faithfully,

A. Banks Raffle, M.D. Durh.

Westoe Village, S. Shields.

\section{THE PROXIMATE FACTOR IN DELIRIUM TREMENS.}

1o the Elitor of THE LANCET.

SIR,-I agree with Dr. F. Hare that the type of inebriety sometimes changes. The periodic may become a regular drunkard. The "regular" drunkard who has to an extent pulled himself together and has only occasional outbreaks I should still classify as "regular." But the "regular" drunkard rarely, if ever, becomes a periodic dipsomaniac. I have already referred in a previous letter to the drugs which I have found most useful in warding off delirium tremens.

I am, Sir, yours faithfully,

Rickmansworth, May 10th, 1909.

F. S. D. HOGG.

\section{AN INFLUENTIAL APPEAL.}

\section{To the Editor of THE LANCET.}

SIR,-We desire to bring under the notice of your readers the case of a registered medical practitioner of many years' standing and in good repute in this city. Owing to circumstances of a family nature, not in the least degree reflecting on his character or on that of any member of his family, and to his indifferent health of late, he is in urgent want of pecuniary help to enable him to maintain his position. We, therefore, venture to appeal for that assistance to the members of bis own profession, who are always willing to help their brother practitioners. Any of the undersigned will be glad to receive any donations that may be kindly sent in response to this urgent appeal.

We are, Sir, yours faithfully,

ANDREW J. HORNE,

Presiclent, Royal College of Physicians of Ireland; JOHN LENTAIGNE,

President, Royal College of Surgeons in Ireland;

Johy W. Moore, M.A., M.D., D.Sc., F.R.C.P.I., 40, Fitzwilliam-square, Dublin;

May 11th, $1909 . \quad 51$, Pembroke-road, Dublin.

\section{THE BUDGET AND THE GENERAL MEDICAL PRACTITIONER.}

To the Editor of THE LANCET.

Sir,-Mr. Winston Churchill in the discussion on the Budget in the House of Commons on Monday is reported in the Daily l'elegraph to have said, "The middle classes are not affected in any perceptible degree except by the death duties." Is this so ? Without entering on the political side of the question, I should like to dispute the above conclusion - that is, if we general practitioners may describe ourselves as belonging to the "middle classes." I have no doubt that there are many, very many, others situated as I am, and I should like to know what they think of the situation. I am a still struggling general practitioner and have been struggling for the last 30 years to keep my head above water, to pay my way, to give my boys and girls such an education as would fit them for some useful place in this world, and, in addition, to attempt to provide a little fund to help in our old age to lessen the severity of the grinding tyranny of badly paid medical practice, and lastly, after death to keep my wife and daughters out of the workhouse.

With regard to this last, one has only to pick up THE LANCET from week to week to read the distressing straits to which delicately nurtured ladies are driven to keep body and soul together after they have been deprived of the breadwinner, perhaps prematurely, before he has had the opportunity of making suitable provision for them. But read, mark, learn! How does a so-called Liberal Government encourage us? I have been in practice for over 30 years and in that time, by dint of struggling, striving, saving, scraping, denying myself almost every luxury, and almost necessaries in the station of life in which it has been my lot to be cast, I have managed to save $£ 2000$. The income from this, if I had been a retired Government servant (probably acting as director of two or three public companies), would have been called "deferred pay," and charged for the purpose of income-tax at the rate of $9 d$. in the $£ 1$, but because I have been thrifty, frugal, and saving at the expense of my comfort and pleasure, a logical Government, bent on bestowing old-age pensions on the deserving and nndeserving alike, chooses to call it "unearned" income and charges me at the rate of $1 s$. $2 d$. for every £1 I receive، Unearned forsooth! When I have tramped on my ten toes from morn till night till my feet ached to earn it! What a premium on thrift! What a satire on consistency! What a parody on justice! Is it possible to argue that thrift is not actually discouraged by such a proceeding? The interest on my little ewe lamb is to be assessed at the same standard as that of those lucky individuals who possess comparatively large incomes although "they toil not neither do they spin."

Again, a portion of my $£ 2000$ has been for many years invested in what appeared to be a safe and fairly remunerative investment--viz., brewery shares. What is the outlook with regard to these? The retort will probably be made that I ought not to have invested in such uncertain security. Perhaps not. Again, with a $3 s .9 d$. addition to the spirit duty, will not our drug bill be considerably increased?

Lastly, we shall be hit by the death duties. What wonder, then, that the professional classes exclaim at the inroads which the exigencies of Government demands make on their scanty means, but to say that we are not affected in any perceptible degree is adding insult to injury, is unjust, and 